\title{
Produtividade de biomassa em sistemas agroflorestais e tradicionais no Cariri Paraibano
}

\author{
Júlio C. R. Martins', Rômulo S. C. Menezes', Everardo V. S. B. Sampaio', \\ Ailton F. dos Santos ${ }^{2} \&$ Mona A. Nagai ${ }^{1}$
}

\begin{abstract}
RESUMO
As produtividades de biomassa de sistemas tradicionais (cultivos de milho e feijão, capim buffel ou palma) e agroflorestais (cultivos entre fileiras de gliricídia ou maniçoba) foram comparadas em experimento em parcelas subdivididas, de 2006 a 2009, em Taperoá, Paraíba. A precipitação média é de $600 \mathrm{~mm}$. Nas parcelas agroflorestais as fileiras de árvores distavam $6 \mathrm{~m}$, com $1 \mathrm{~m}$ entre árvores. No sistema tradicional, os cultivos produziram 33\% mais biomassa e a biomassa de milho e feijão foi o dobro da produzida nos sistemas agroflorestais. O capim buffel foi o cultivo que mais produziu no sistema agroflorestal. No sistema tradicional os cultivos que mais produziram foram buffel e consórcio milho e feijão. A gliricídia produziu nove vezes mais biomassa de folhas, galhos finos e lenha que a maniçoba. Incluindo essas biomassas, a produtividade total nos sistemas agroflorestais foi $260 \%$ maior que nos sistemas tradicionais. Os coeficientes de variação da produtividade anual de biomassa foram menores nos sistemas agroflorestais. Portanto, a presença de árvores não só aumentou a produtividade total como conferiu maior estabilidade aos sistemas.
\end{abstract}

Palavras-chave: agroecosisstemas, semiárido, Manihot glaziovii, Gliricidia sepium

\section{Biomass productivity in agroforestry and traditional systems in the 'Cariri Paraibano'}

\begin{abstract}
The biomass productivity of traditional systems (corn and beans, buffel grass and prickly pear cactus) and agroforestry systems (crops betwenn lines of gliricídia or maniçoba) were compared in a split plot experiment, during 2006 to 2009, in Taperoá, Paraíba, Brazil. Mean annual rainfall in the region is 600 $\mathrm{mm}$. The agroforestry alleys were $6 \mathrm{~m}$ apart with $1 \mathrm{~m}$ between trees. In the traditional systems, the crops produced $33 \%$ more biomass and the corn and beans double the biomass of the agroforestry systems. Buffel grass was the most productive crop in the agroforestry systems. In the traditional systems, buffel and intercrops corn and beans were the most productive crops. Gliricidia produced nine times more leaf, twig and fuel wood biomass than maniçoba. Including these biomasses the productivity of the agroforestry systems was $260 \%$ higher than that of the traditional systems. The coefficient of variation of the annual biomass productivity was lower for the agroforestry systems. Therefore, the presence of trees increases not only the productivity but also the stability of the systems.
\end{abstract}

Key words: agroecosystems, semiarid, Manihot glaziovii, Gliricidia sepium 


\section{INTRODUÇÃO}

Durante o processo de ocupação da região semiárida paraibana a agricultura de subsistência, principalmente com cultivo de milho, feijão e mandioca e a criação animal foram, por muito tempo, os principais sistemas de uso da terra (Silva \& Menezes, 2010). Posteriormente, o crescimento demográfico, a evolução da estrutura fundiária e uma sucessão de cultivos comerciais (algodão, sisal, fumo, batata inglesa e mamona) que variaram nas distintas mesorregiões, exerceram uma forte pressão sobre os recursos naturais (Silva et al., 2007).

Dentre as consequências mais visíveis deste processo de ocupação e uso do solo no semiárido paraibano, estão a eliminação da vegetação nativa e a redução da presença de espécies arbóreas nos agroecossistemas. Diversos estudos indicam que a eliminação da cobertura arbórea geralmente leva à redução dos teores de matéria orgânica, dos nutrientes do solo e da infiltração de água da chuva no solo e, em consequência, produz aumento na taxa de erosão (Sampaio \& Menezes, 2003). Além disto, pode ocorrer diminuição da biodiversidade dos agroecossistemas pois certos organismos da fauna e da flora, associados às espécies arbóreas ou ao ambiente de caatinga, perdem nichos essenciais à sua preservação (Sampaio et al., 2009).

Para minimizar a fragilidade dos sistemas de produção tradicionais e o efeito da retirada de total de árvores nas áreas de cultivo da região semiárida paraibana, diversos agricultores estão fazendo uso dos sistemas agroflorestais. Esses sistemas são práticas de agrossilvicultura que estão sendo exploradas como opções de uso da terra em diversas áreas do mundo (Ngegba et al., 2007; Wick \& Tiessen, 2008).

Dentre os vários tipos de sistemas agroflorestais há o "cultivo em aleias", no qual espécies arbustivas ou arbóreas, geralmente leguminosas (Freitas et al., 2010) são plantadas em fileiras e as culturas agrícolas são estabelecidas entre as fileiras (Pérez-Marin et al., 2007). As árvores ou arbustos sãopodados periodicamente e a biomassa da poda é incorporada ao solo; com isto, ocorre transferência de nutrientes das árvores para as culturas anuais (Nair, 1993) e diminuiçãode competição por luz, água e nutrientes dentro do sistema.

Visando quantificar as relações solo-planta em sistemas silvipastoris, vários estudos recentes têm demonstrado que a diminuição da fertilidade do solo nos agroecossistemas do semiárido pode ser revertida/prevenida, através da introdução/ preservação de espécies arbóreas.

A avaliação da fertilidade do solo em sistemas silvipastoris em Custódia, no Sertão pernambucano, mostrou a ocorrência de "ilhas de fertilidade" nas áreas sob a influência das copas de árvores presentes em pastagens de capim buffel. Verificou-se, nesses estudos, que o plantio de algaroba (Prosopis juliflora) ou a preservação do juazeiro (Ziziphus joazeiro) nas pastagens aumentou os níveis de matéria orgânica e nutrientes na camada superficial do solo. Além disto, houve aumento na produção de biomassa pelas herbáceas sob a copa do juazeiro e diminuição na biomassa do estrato herbáceo sob a copa da algaroba, fato que pode ser devido à competição por água nas camadas mais superficiais do solo (Menezes \& Salcedo, 1999; Menezes et al., 2002).
Em outro estudo com sistemas agrosilvopastoris na região semiárida da Paraíba a introdução de espécies arbóreas em campos agrícolas e pastagens promoveu aumento na produtividade de biomassa em até 200\% (Pérez-Marin et al., 2007); entretanto, ainda é pouca a informação disponível sobre os efeitos do aumento da diversidade de espécies (herbáceas, arbustivas e arbóreas) nos agroecossistemas da região semiárida sobre a produção de biomassa.

Neste contexto há necessidade de maior conhecimento sobre os usos e o manejo de espécies arbóreas em propriedades rurais na região semiárida, ou seja, quanto às potencialidades de implantação de sistemas agrosilvipastoris nesta região. Assim, o objetivo do presente trabalho foi comparar a produtividade de biomassa em sistemas agroflorestais ou convencionais (sem árvores) no semiárido paraibano.

\section{Material e Métodos}

O estudo foi conduzido na Estação Agroecológica Vila Maria Rita, em torno das coordenadas $7^{\circ} 12^{\prime} 23^{\prime \prime}$ de latitude Sul e $36^{\circ} 49^{\prime} 25^{\prime \prime}$ de longitude Oeste $\mathrm{Gr}$, com altitude média de 532 m, no município de Taperoá, PB, no período de 2006 a 2009 . O município tem clima semiárido, com temperatura média anual de $30^{\circ} \mathrm{C}$ e precipitação média de $600 \mathrm{~mm}$. Os totais anuais de precipitação pluviométrica em 2006, 2007, 2008 e 2009, foram 987, 533, 725 e $756 \mathrm{~mm}$, respectivamente (Figura 1).

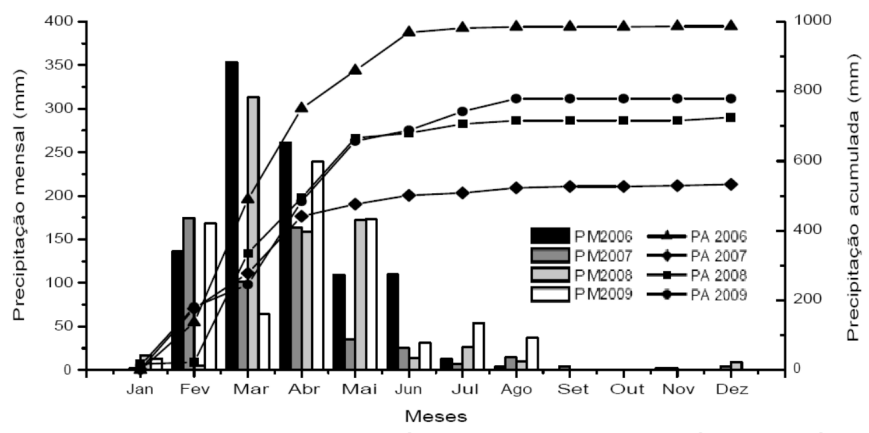

Figura 1. Precipitação pluviométrica mensal e anual acumulada no centro agroecológico

$\mathrm{Na}$ área experimental o solo é classificado como Neossolo Flúvico, com caracterização química e física descrita na Tabela 1, de acordo com (Sousa, 2009). As metodologias utilizadas para caracterização dos atributos químicos e físicos do solo foram propostas e descritas pela EMBRAPA (1999) seguindo os procedimentos: $\mathrm{pH}$ em $\mathrm{H}_{2} \mathrm{O}$ (solo: 2,5 água, $\mathrm{v} \mathrm{v}^{-1}$ ); $\mathrm{Ca}^{+2}{\mathrm{e} \mathrm{Mg}^{+2}}^{+2}$ (extraídos com $\mathrm{KCl}$ e determinados por absorção atômica); $\mathrm{P}, \mathrm{K}^{+}$e $\mathrm{Na}$ (extraídos com Mehlich-1 e determinados $\mathrm{K}^{+}$e $\mathrm{Na}$ por fotometria de chama e o P por colorimetria); C orgânico (determinado por oxidação úmida em dicromato de potássio) e granulometria, pelo método do densímetro.

$\mathrm{O}$ experimento foi conduzido em blocos ao acaso, em parcelas subdivididas, com quatro repetições. Os tratamentos principais consistiram em dois sistemas agroflorestais, cultivo agrícola com a presença de árvores (CA) e cultivo agrícola convencional, sem árvores (SA) e os três tratamentos secundários consistiram em três tipos de cultura (consórcio feijão + milho, capim buffel e palma). Os espaçamentos nos 
Tabela 1. Atributos químicos e físicos do solo em dois sistemas de uso da terra com árvores (CA) e sem árvores (SA), submetidas a três diferentes sistemas de uso da terra no semiárido paraibano, em Taperoá, PB, 2007

\begin{tabular}{|c|c|c|c|c|c|c|c|c|c|c|c|}
\hline \multirow{3}{*}{ Sistemas } & \multirow{3}{*}{ Cultivos } & \multirow{3}{*}{$\begin{array}{c}\mathrm{pH} \\
\mathrm{H}_{2} \mathrm{O}\end{array}$} & \multirow{3}{*}{$\begin{array}{c}\mathbf{P} \\
\mathbf{m g ~ k g}{ }^{-1}\end{array}$} & \multirow{2}{*}{ K } & \multirow{2}{*}{$\mathrm{Na}$} & \multirow{2}{*}{$\mathrm{Ca}$} & \multirow{2}{*}{$\mathrm{Mg}$} & \multirow{2}{*}{ C.0. } & \multicolumn{3}{|c|}{ Granulometria } \\
\hline & & & & & & & & & Areia & Argila & Silte \\
\hline & & & & \multicolumn{4}{|c|}{$\mathrm{cmol}_{\mathrm{C}} \mathrm{kg}^{-1}$} & \multicolumn{4}{|c|}{$\mathrm{g} \mathrm{kg}^{-1}$} \\
\hline \multirow{3}{*}{$\begin{array}{l}\text { Com } \\
\text { árvores }\end{array}$} & Milho + feijão & 7,69 & 77,45 & 0,55 & 0,16 & 9,02 & 1,61 & 7,82 & $698^{\circ}$ & 172 & 130 \\
\hline & Buffel & 7,70 & 65,23 & 0,50 & 0,31 & 5,84 & 0,99 & 9,51 & 685 & 172 & 143 \\
\hline & Palma & 7,46 & 72,30 & 0,43 & 0,18 & 6,53 & 0,90 & 10,34 & 658 & 182 & 160 \\
\hline \multirow{3}{*}{$\begin{array}{l}\text { Sem } \\
\text { árvores }\end{array}$} & Milho + feijão & 7,15 & 51,63 & 0,51 & 0,12 & 6,42 & 1,03 & 8,05 & 665 & 185 & 150 \\
\hline & Buffel & 7,30 & 78,91 & 0,63 & 0,16 & 5,71 & 0,84 & 9,47 & 723 & 147 & 130 \\
\hline & Palma & 7,09 & 60,81 & 0,41 & 0,17 & 7,15 & 1,16 & 8,13 & 633 & 197 & 170 \\
\hline
\end{tabular}

C.0. - Carbono orgânico

cultivos de feijão + milho foram de $1 \mathrm{~m}$ entre fileiras e $0,25 \mathrm{~m}$ entre plantas; a palma, de $1 \mathrm{~m}$ entre fileiras e $0,5 \mathrm{~m}$ entre plantas e o de capim buffel de $0,5 \mathrm{~m}$ entre fileiras e $0,1 \mathrm{~m}$ entre plantas. Os espaçamentos propostos foram baseados nos utilizados pelos agricultores da região.

O experimento foi instalado no início da estação de chuvas de 2006, em parcelas experimentais de $6 \times 10 \mathrm{~m}$, com os seguintes tipos de agroecossistemas: 1) sistema de cultivo agrícola tradicional com espécies herbáceas anuais: consórcio de milho (Zea mays L., var. Sergipano) e feijão (Vigna unguiculata (L.) Walp var. Moitinha); 2) sistemas de produção de forragem com espécie herbácea perene: capim buffel (Cenchrus ciliaris) e 3) sistemas de produção de forragem com palma (Opuntia ficus-indica). Para cada um dos sistemas de produção foram estabelecidas, também, parcelas agroflorestais com dimensões de 10 × 30 m com fileiras de gliricídia (Gliricidia sepium (Jacq.) Steud) e maniçoba (Manihot glaziovii Muel Arg.) intercaladas com espaçamento de $1 \mathrm{~m}$ entre as árvores de cada espécie na mesma fileira e com espaçamento de $6 \mathrm{~m}$ entre fileiras. Os espaçamentos do milho e feijão, buffel e palma foram nas parcelas agroflorestais, os mesmos que no cultivo tradicional, sem árvores.

A gliricídia e a maniçoba foram estabelecidas transplantandose mudas, em fevereiro de 2006. No momento do transplantio das mudas as parcelas foram adubadas com esterco bovino curtido espalhado uniformemente em toda a área experimental, em dose equivalente a $10 \mathrm{Mg} \mathrm{ha}^{-1}$. $\mathrm{O}$ esterco bovino utilizado apresentou em média $12 \mathrm{~g} \mathrm{~kg}^{-1}$ de $\mathrm{N}, 6,5 \mathrm{~g} \mathrm{~kg}^{-1}$ de $\mathrm{P}$ e $27 \mathrm{~g} \mathrm{~kg}^{-1}$ de K (EMBRAPA, 1999; Garrido, 2009); em seguida, foram plantados milho e feijão, buffel e palma forrageira. A palma foi plantada enterrando-se parcialmente cladódios retirados de plantas crescidas em local próximo. Nos anos subsequentes o plantio do milho e do feijão foi realizado sempre no início do período chuvoso, em fevereiro ou março. Foram realizadas Capinas manuais foram realizadas sempre que necessário. Ao longo do experimento ocorreram ataques de insetos, principalmente no milho e no capim buffel, em 2009, mas foram controlados com pulverização com óleo de nimindiano.

A quantificação da biomassa das ramas de gliricídia e de maniçoba foi realizada em 2008 e 2009. Nos dois primeiros anos as árvores ainda não tinham atingido porte adequado para poda. Visando à quantificação de biomassa, as árvores (gliricídia e maniçoba) foram podadas com facão na altura de aproximadamente $1,5 \mathrm{~m}$ do solo, deixando-se um tronco. A poda foi realizada uma semana antes do plantio das culturas anuais (em fevereiro ou março de cada ano). Após a poda a biomassa retirada foi separada em folhas (incluindo galhos finos com diâmetro $<1,5 \mathrm{~cm}$ ) e lenha (todos os galhos com diâmetro $>1,5$ $\mathrm{cm}$ ); prosseguindo, ambas as frações foram pesadas com auxílio de balança portátil (Capacidade de $20 \mathrm{~kg}$ ). Subamostras de folhas e galhos finos foram retiradas e submetidas à secagem em estufa de circulação forçada a $65^{\circ} \mathrm{C}$, por $72 \mathrm{~h}$ para determinação do teor de matéria seca.

Referente à quantificação da biomassa do feijão e milho, a colheita foi realizada aos 60 e 120 dias após o plantio (DAP) respectivamente; em seguida se separou, para o milho, a parte aérea das plantas em grãos e palhada (sabugo + pendão + palha), determinou-se o peso úmido das amostras e se retirou uma subamostra, que foi submetida à secagem em estufa de circulação forçada a $65^{\circ} \mathrm{C}$,durante $72 \mathrm{~h}$, para quantificação do teor de matéria seca. A produtividade de grãos foi expressa com umidade de $12 \%$. Para o feijão, separou-se a biomassa da parte aérea em grãos e palha e, em seguida, realizaram-se os mesmos procedimentos adotados para as amostras de milho, com vista à determinação da matéria seca.

Para quantificação da produção de biomassa do capim buffel utilizou-se um gabarito com área de $0,25 \mathrm{~m}^{2}$, pesou-se a biomassa contida na área delimitada pelo gabarito e se retiraram subamostras as quais foram colocadas em estufa de circulação forçada a $65^{\circ} \mathrm{C}$, por $72 \mathrm{~h}$, para determinação do teor de matéria seca. Nas parcelas sob sistema agroflorestal (CA) o gabarito foi lançado 30 vezes. Nas parcelas com cultivo convencional ou sem árvores (SA) realizou-se o mesmo procedimento sendo o gabarito lançado apenas 5 vezes em cada parcela devido à menor dimensão das parcelas.

A palma forrageira foi conduzida em ciclo de crescimento de três anos, tendo sido cortada a primeira vez no final do período chuvoso de 2008, deixando-se três cladódios por planta; de vez que o ciclo foi de três anos, a produtividade média anual foi calculada dividindo-se a biomassa de 2008 por três. Realizouse a pesagem dos cladódios e se quantificou a biomassa verde total em cada parcela; em seguida, uma subamostra foi retirada e submetida a secagem, primeiro ao sol, para retirada inicial da umidade, e depois em estufa de circulação forçada a $65^{\circ} \mathrm{C}$ por $72 \mathrm{~h}$, para quantificação do teor de matéria seca.

A análise estatística da biomassa das árvores (folhas + galhos finos e lenha) foi feita separadamente por análise de variância de blocos ao acaso, com quatro repetições, após verificação da normalidade dos dados. As médias obtidas foram comparadas pelo teste de Tukey a 0,05 de probabilidade utilizando-se o programa estatístico SISVAR (Ferreira, 2003). 


\section{Resultados E Discussão}

A produtividade total de matéria seca (MS) das espécies cultivadas (milho/feijão, buffel e palma) ao longo dos quatro anos do experimento (Tabela 2) foi cerca de 33\% maior no sistema sem árvore (SA) que no sistema com árvores (CA). Entretanto, dentre os cultivos o milho + feijão (é um cultivo milho + feijão) é composto das únicas espécies que produziram significativamente menos biomassa no sistema CA com redução de cerca de $38 \%$. Esta redução é esperada uma vez que a presença de árvores afeta diretamente a produtividade das culturas associadas pela competição por água, nutrientes e luz (Sanchez, 1995; Pérez-Marin et al., 2007).

Tabela 2. Produtividade de biomassa, em matéria seca $\left(\mathrm{kg} \mathrm{ha}^{-1}\right)$ em dois diferentes sistemas de uso da terra, com árvores (CA) e sem árvores (SA) sob três diferentes cultivos, em quatro anos consecutivos, em Taperoá, PB

\begin{tabular}{|c|c|c|c|c|c|}
\hline \multirow{2}{*}{ Sistema } & \multirow{2}{*}{ Cultivos } & 2006 & 2007 & 2008 & 2009 \\
\hline & & \multicolumn{4}{|c|}{$\mathrm{kg} \mathrm{ha}^{-1}$} \\
\hline \multirow{3}{*}{$\begin{array}{l}\text { Com } \\
\text { árvores }\end{array}$} & Milho + Feijão $0^{(1)(2)}$ & $4.390 \mathrm{a}$ & $254 \mathrm{a}$ & $4.644 \mathrm{a}$ & $3.646 \mathrm{~b}$ \\
\hline & Buffel & $2.119 \mathrm{a}$ & $D P^{(3)}$ & $6.241 b$ & $7.747 \mathrm{a}$ \\
\hline & Palma & - & - & $4.257 \mathrm{a}$ & - \\
\hline \multirow{3}{*}{$\begin{array}{c}\text { Sem } \\
\text { árvores }\end{array}$} & Milho + Feijão & $3.795 \mathrm{a}$ & $233 \mathrm{a}$ & $5.195 \mathrm{a}$ & $11.616 \mathrm{a}$ \\
\hline & Buffel & $1.455 \mathrm{a}$ & $\mathrm{DP}$ & $10.386 a$ & $7.896 \mathrm{a}$ \\
\hline & Palma & - & - & $4.764 \mathrm{a}$ & - \\
\hline
\end{tabular}

(1) Letras minúsculas na coluna comparam médias de produtividade de matéria seca de cada cultivo, entre os sistemas. Letras iguais na coluna não diferem estatisticamente pelo teste de Tukey a 0,05 de probabilidade. (2) Somatório de grão e palhada de ambas as espécies (milho e feijão). ${ }^{(3)}$ DP: Dados perdidos

No ano de 2006 os sistemas apresentaram comportamentos semelhantes (Tabela 2) o que pode ser devido ao pequeno tamanho das mudas das espécies arbóreas, que deviam apresentar menor grau de competitividade com as espécies cultivadas. Pérez-Marin et al. (2007) observaram, em estudo no semiárido paraibano, reduções significativas na produtividade de grãos e palhada do milho quando em consórcio com aleias de gliricídia, em três anos consecutivos porém neste estudo as árvores do experimento já tinham cerca de sete anos de idade antes do primeiro ano do experimento e já exerciam forte competição por água, luz e nutrientes.

Outra vertente a ser considerada é que a ausência de diferenças significativas entre a produtividade de biomassa nos CA e SA no ano de 2006 pode estar relacionada à alta precipitação pluviométrica desse período, que foi de $986 \mathrm{~mm}$ (Figura 1), fazendo com que a competição por água não fosse fator limitante para o crescimento dos cultivos em consórcio. Segundo Sanchez (1995) os cultivos em aleia só são capazes de aumentar a produtividade das culturas agrícolas associadas em regiões úmidas e de solos férteis nos quais a competição por água e nutrientes entre as árvores e as culturas agrícolas é reduzida.

Em 2007, ano de baixa precipitação pluviométrica $(533 \mathrm{~mm}$, Figura 1) não houve produção de feijão nem foi quantificada a biomassa do buffel em virtude da perda das amostras coletadas; portanto, quantificou-se apenas a produtividade do milho, que foi muito baixa, 254 e $228 \mathrm{~kg} \mathrm{ha}^{-1} \mathrm{MS}$ para os sistemas CA e $\mathrm{SA}$, respectivamente (Tabela 2 ).

A partir de 2008 foi possível verificar efeito significativo para os cultivos entre os sistemas. A produtividade média de biomassa em 2008 no sistema SA foi de $6.782 \mathrm{~kg} \mathrm{ha}^{-1}$ de MS, $35 \%$ maior que no sistema CA, que foi de $5.047 \mathrm{~kg} \mathrm{ha}^{-1}$ de MS (Tabela 2). Em números absolutos, essa diferença foi de $1.737 \mathrm{~kg} \mathrm{ha}^{-1}$. Valores semelhantes foram encontrados por Pérez-Marin et al. (2007) que observaram reduções de 1.282 e de $1.960 \mathrm{~kg} \mathrm{ha}^{-1}$ na produtividade de grãos e de palhada de milho,respectivamente, em parcelas com árvores em relação às sem árvores.

Para o buffel, no sistema SA a produtividade de biomassa em 2008 foi de $10.386 \mathrm{~kg} \mathrm{ha}^{-1}, 40 \%$ maior que no sistema CA, que foi de $6.241 \mathrm{~kg} \mathrm{ha}^{-1}$ (Tabela 2). Esses níveis de produtividade do sistema SA (sistema tradicional de cultivo da região) estão dentro da faixa observada na região nordeste que, de acordo com Oliveira (1981), oscila entre 8.000 e $12.000 \mathrm{~kg} \mathrm{ha}^{-1} \mathrm{ano}^{-1}$. Considerando esta faixa, a produtividade no sistema CA estaria abaixo mas isto leva em conta apenas a produtividade das culturas sem adicionar a produtividade das árvores. Já Moreira et al. (2007) observaram, avaliando o potencial de produção do capim buffel na época seca no semiárido pernambucano, uma produtividade de biomassa 3.356 a $6.492 \mathrm{~kg} \mathrm{ha}^{-1} \mathrm{de}$ MS; entretanto, Oliveira (1981) afirmou que a produtividade das diversas variedades de capim buffel é muito variável e está associada à maior ou menor adaptação às condições edafoclimáticas prevalentes nos locais.

Avaliando de forma mais detalhada a produtividade média anual do milho e do feijão, observou-se maior produtividade no sistema SA que no sistema CA (Tabela 3). Isto pode ser explicado em consequência da competição dos cultivos associados com as árvores, como pode ser verificado em outros estudos (Reynolds et al., 2007; Prasad et al., 2010). Nos sistemas SA as médias de produtividade anual do milho e do feijão foram 91 e $95 \%$ maiores, respectivamente, que no CA.

Os valores de produtividade de grãos do milho foram próximos aos da média da região $700 \mathrm{~kg} \mathrm{ha}^{-1}$ (Mundus et al., 2008) e bem abaixo dos reportados em alguns estudos da região (Menezes \& Salcedo, 2007; Pérez-Marin et al., 2007).

Neste ano de 2008 pôde-se comparar, com a colheita da palma, as produtividades das três culturas. No sistema CA a cultura que mais produziu biomassa foi o buffel e a que menos produziu biomassa foi a palma, mesmo tendo acumulado biomassa ao longo dos três anos do ciclo de crescimento. Apenas em 2008 a biomassa do consórcio milho+feijão não se diferenciou estatisticamente da biomassa da palma mas, se somadas as produções dos anos anteriores, seria o dobro.

Em ambas as espécies as produtividades de grão e palhada não diferiram significativamente entre os sistemas SA e CA (Tabela 3) para os três primeiros anos (2006, 2007 e 2008); em 2007 as produtividades de grãos do milho foram semelhantes às encontradas por Santos et al. (2010), no mesmo ano, em outro local do semiárido paraibano,quando avaliaram o efeito residual de adubação orgânica com esterco e gliricídia sobre a produtividade do milho em sistema agroflorestal, encontrando produtividades de 36 e $15 \mathrm{~kg} \mathrm{ha}^{-1}$ MS nos tratamentos com gliricídia e controle (sem adubação) respectivamente.

Em 2007 as produtividades de grãos de milho e de feijãoforam drasticamente reduzidas pelo déficit hídrico no decorrer do período de desenvolvimento das culturas.Apesar de muito baixa, foi possível a quantificação da produtividade 
Tabela 3. Produtividade de matéria seca em $\left(\mathrm{kg} \mathrm{ha}^{-1}\right)$ de palhada e grão de milho e feijão, em dois sistemas de uso da terra, com árvores (CA) ou sem árvores $(\mathrm{SA})$ por quatro anos consecutivos

\begin{tabular}{|c|c|c|c|c|c|c|c|c|c|c|c|}
\hline \multirow{3}{*}{ Sistema } & \multirow{3}{*}{ Cultura } & \multicolumn{2}{|c|}{2006} & \multicolumn{2}{|c|}{2007} & \multicolumn{2}{|c|}{2008} & \multicolumn{2}{|c|}{2009} & \multicolumn{2}{|c|}{ Médiaanual } \\
\hline & & Grão & Palha & Grão & Palha & Grão & Palha & Grão & Palha & Grão & Palha \\
\hline & & \multicolumn{10}{|c|}{$\mathrm{kg} \mathrm{ha}^{-1}$} \\
\hline \multirow{3}{*}{ Com árvores } & Milho & $978 a^{(1)}$ & $3.034 \mathrm{a}$ & $46 a$ & $208 \mathrm{a}$ & $839 a$ & $1.766 \mathrm{a}$ & $802 b$ & $2.796 \mathrm{~b}$ & $718 \mathrm{a}$ & $1.976 \mathrm{~b}$ \\
\hline & Feijão & $125 \mathrm{a}$ & $28 \mathrm{a}$ & 0 & $\mathrm{DP}$ & $131 \mathrm{a}$ & $41 a$ & $36 \mathrm{a}$ & $11 \mathrm{a}$ & $98 \mathrm{a}$ & $26 a$ \\
\hline & Média & $551 \mathrm{~A}$ & $1.531 \mathrm{~A}$ & & & $485 \mathrm{~A}$ & $904 \mathrm{~A}$ & $419 \mathrm{~B}$ & $1.403 \mathrm{~B}$ & $408 \mathrm{~B}$ & $1.279 \mathrm{~A}$ \\
\hline \multirow{3}{*}{ Semárvores } & Milho & $840 \mathrm{a}$ & $2.800 \mathrm{a}$ & $16 \mathrm{a}$ & $217 a$ & $1.192 \mathrm{a}$ & $3.591 \mathrm{a}$ & $2.753 \mathrm{a}$ & $8.329 \mathrm{a}$ & $1.199 \mathrm{a}$ & $3.708 \mathrm{a}$ \\
\hline & Feijão & $126 \mathrm{a}$ & $30 a$ & 0 & DP & $264 a$ & $146 a$ & $410 \mathrm{a}$ & $123 \mathrm{a}$ & $267 \mathrm{a}$ & $100 \mathrm{a}$ \\
\hline & Média & $482 \mathrm{~A}$ & $1.414 \mathrm{~A}$ & & & $728 \mathrm{~A}$ & $1.869 \mathrm{~A}$ & $1.582 \mathrm{~A}$ & $4.226 \mathrm{~A}$ & $733 \mathrm{~A}$ & $2.503 \mathrm{~A}$ \\
\hline
\end{tabular}

(1) Letras minúsculas na coluna comparam uma cultura dentro de cada sistema. Letras maiúsculas na coluna comparam médias de cada cultura dentro de cada sistema. Letras iguais na mesma coluna não diferem estatisticamente pelo teste de Tukey a 0,05 de probabilidade; DP - Dados perdidos

do milho devido, provavelmente, ao seu maior ciclo fenológico, em média 120 dias. O déficit hídrico ocorreu no momento vegetativo quando a cultura do milho é relativamente tolerante e não no momento do enchimento dos grãos quando é extremamente sensível (Kasele et al., 1994). Para o feijão, a produtividade de grãos foi totalmente perdida.

Em 2009 foram observadas, mas apenas para o milho, diferenças significativas nas produtividades de grãos e palhada entre os tratamentos CA e AS; no caso dos grãos o sistema SA produziu $243 \%$ mais que o sistema CA; já para a palhada, a produtividade foi de $2.796 \mathrm{~kg} \mathrm{ha}^{-1}$ de MS no sistema CA e 8.329 $\mathrm{kg} \mathrm{ha}^{-1}$ no sistema SA, uma produtividade $197 \%$ maior que a do sistema SA (Tabela 3).

Em estudo semelhante no semiárido paraibano, Pérez-Marin et al. (2007) observaram redução significativa no sistema CA em relação ao SA, tanto de grãos quanto de palhada. Esta redução na produtividade do milho no sistema CA foi, em média, 164 e $77 \%$ menor que no sistema SA, para grãos e palhada, respectivamente;em outro estudo avaliando o rendimento da cultura do milho em sistemas agroflorestais, Siriri et al. (2010) constataram redução maior que $50 \%$ quando consorciada com Calliandra calothyrsus; entretanto, o estudo foi conduzido em área com precipitação pluviométrica de $1.000 \mathrm{mmano}^{-1}$, bem distribuídos.

Percebe-se, ao comparar os índices de colheita (IC proporção entre a biomassa de grãos e a biomassa aérea total da planta)que o IC no sistema CA foi de $28 \%$ enquanto no sistema SA foi em média 33\%. Esta observação é coerente com os resultados obtidos no estudo realizado por Muthuri et al. (2005) que, cultivando milho consorciado com diversas espécies arbóreas, em duas localidades no Quênia, observaram que a presença das árvores afetoumais a produtividade de grãos que a de palhada influenciando diretamente no índice de colheita do milho.

Em 2008, quando as árvores já tinham atingido maior porte, de forma que os galhos já invadiam grande parte da área a ser ocupada pelas espécies cultivadas, foi realizada a primeira poda; em 2009, a poda foi repetida; a produtividade média anual de biomassa de folhas e galhos finos de gliricídia e maniçoba em 2008 e 2009 e independente do sistema de uso da terra, foi de $2.095 \mathrm{~kg} \mathrm{ha}^{-1}$ de massa seca (Tabela 4).

Separadamente em cada sistema de cultivo, a avaliação da produtividade das espécies arbóreas mostrou que em 2008 e 2009 a produtividade média de folhas e galhos finos no sistema de cultivo milho + feijão, igual a $2.776 \mathrm{~kg} \mathrm{ha}^{-1}$, foi maior que nas parcelas com buffel e palma, quando as árvores produziram, em média, 1.582 e $1.928 \mathrm{~kg} \mathrm{ha}^{-1}$ ano $^{-1}$, respectivamente (Tabela 4).

Mais especificamente, salienta-se que a produtividade das árvores no sistema com o buffel foi 75 e $22 \%$ menor que nos sistema milho + feijão e palma, respectivamente, fato passível de ser devido ao buffel exercer uma competição mais forte pelos recursos disponíveis com as espécies arbóreas (Tabela 4). Portanto, conclui-se que a competição pelas espécies cultivadas pode exercer influência significativa sobre a produtividade das espécies arbóreas em sistemas agroflorestaisno semiárido.

A gliricídia produziu mais biomassa de folhas e galhos finos que a maniçoba em todos os sistemas de uso da terra. A produtividade média anual da gliricídia foi de $1.910 \mathrm{~kg} \mathrm{ha}^{-1}$, $926 \%$ maior que a da maniçoba $\left(186 \mathrm{~kg} \mathrm{ha}^{-1}\right)$. Valores médios semelhantes de produtividade de biomassa de folhas de Manihot

Tabela 4. Produtividade de biomassa (folhas e galhos finos $<1,5 \mathrm{~cm}$ ) e lenha (em $\mathrm{kg} \mathrm{ha}^{-1}$ de massa seca) de maniçoba e gliricídia, em um sistema agroflorestal sob três diferentes cultivos (milho + feijão, buffel e palma)

\begin{tabular}{|c|c|c|c|c|c|c|c|}
\hline \multirow{2}{*}{$\begin{array}{l}\text { Sistema de } \\
\text { usoda terra }\end{array}$} & \multicolumn{2}{|c|}{2008} & \multicolumn{2}{|c|}{2009} & \multicolumn{2}{|c|}{ Médiaanual } & \multirow{2}{*}{$\begin{array}{c}\text { Média } \\
\text { anual total }\end{array}$} \\
\hline & Maniçoba & Gliricídia & Maniçoba & Gliricídia & Maniçoba & Gliricídia & \\
\hline Milho + Feijão & $245 \mathrm{Ba}^{(1)}$ & $1.230 \mathrm{Aa}$ & $139 \mathrm{Ba}$ & $3.938 \mathrm{Aa}$ & $192 \mathrm{Ba}$ & $2.584 \mathrm{Aa}$ & $2.776 \mathrm{a}$ \\
\hline Palma & $446 \mathrm{Ba}$ & $1.058 \mathrm{Aa}$ & $99 \mathrm{Ba}$ & $2.253 \mathrm{Ab}$ & $272 \mathrm{Ba}$ & $1.656 \mathrm{Ab}$ & $1.928 b$ \\
\hline Média & $262 B$ & $1.018 \mathrm{~A}$ & $109 \mathrm{~B}$ & $2.801 \mathrm{~A}$ & $186 \mathrm{~B}$ & $1.910 \mathrm{~A}$ & 2.095 \\
\hline \multicolumn{8}{|l|}{ Lenha $\left(\mathrm{kg} \mathrm{ha}^{-1}\right)$} \\
\hline Palma & 4.205 Ba & $10.918 \mathrm{Aa}$ & $302 \mathrm{Ba}$ & $14.334 \mathrm{Aa}$ & $2.254 \mathrm{Ba}$ & $12.626 \mathrm{Aa}$ & $14.880 \mathrm{a}$ \\
\hline Média & $1.974 \mathrm{~B}$ & $9.344 \mathrm{~A}$ & $237 \mathrm{~B}$ & $12.314 \mathrm{~A}$ & $1.105 \mathrm{~B}$ & $10.829 \mathrm{~A}$ & 11.935 \\
\hline
\end{tabular}

(1) Letras minúsculas na coluna comparam a produtividade de biomassa de cada espécie florestal sob os três diferentes sistemas de uso da terra. Letras maiúsculas na linha comparam produtividades de biomassa entre espécie florestal. Letras iguais não diferem estatisticamente pelo teste de Tukey a 0,05 de probabilidade 
glaziovii foram encontrados na região central semiárida da Tanzânia, por Shirima et al. (2002) ao observar uma média de $187 \mathrm{~kg} \mathrm{ha}^{-1}$.Em outro estudo conduzido em Petrolina, PE, sobre o crescimento, produtividade e composição de três espécies do gênero Manihot (mandioca, maniçoba e pornunça) a maniçoba apresentou, com um ano de idade, produtividade média de 100 $\mathrm{kg} \mathrm{ha}^{-1} \mathrm{MS}$ (Ferreira et al., 2009).

Dentre os três sistemas de uso da terra o consórcio milho + feijão favoreceu a produção de biomassa de folhas e galhos finos da gliricídia. A biomassa acumulada de $2.584 \mathrm{~kg} \mathrm{ha}^{-1}$ foi 173 e $156 \%$ maior que a acumulada no consórcio da gliricídia com buffel e com a palma, respectivamente (Tabela 4). A produtividade média de folhas e galhos finos da maniçoba não apresentou diferença entre os tratamentos milho + feijão, buffel e palma. Em 2008 e 2009 as médias de produtividade de gliricídia foram de $1.018 \mathrm{e} 2.801 \mathrm{~kg} \mathrm{ha}^{-1} \mathrm{MS}$, respectivamente; apesar disto, no sistema com milho + feijão, no ano de 2009 , a produtividade da gliricídia foi de $3.938 \mathrm{~kg} \mathrm{ha}^{-1} \mathrm{MS}$.

Resultados semelhantes foram encontrados por PérezMarin et al.(2007), nas mesmas condições de clima semiárido:produtividade média de gliricídia em consórcio com o milho e sem adubação de $3.865 \mathrm{~kg} \mathrm{ha}^{-1}$ de MS de folhas e galhos finos. Já Barreto \& Fernandes (2001) utilizando espaçamento de $3 \mathrm{~m}$ entre linhas e $1 \mathrm{~m}$ entre plantas observaram, em tabuleiro costeiro sobre Latossolo Amarelo no município de Lagarto, em Sergipe, uma produtividade média de folhas e galhos tenros de $2.680 \mathrm{~kg} \mathrm{ha}^{-1} \mathrm{MS}$. Em um experimento conduzido por Heriksen et al. (2002) em Turrialba, Costa Rica, com alta precipitação $(2.640 \mathrm{~mm})$ e solos com bom nível de fertilidade, as produtividades médias foram de 14,4 tha-1 MS.

A produtividade média anual total de lenha da gliricídia e da maniçoba nos anos de 2008 e 2009 , foi de $11.935 \mathrm{~kg} \mathrm{ha}^{-1}$ MS (Tabela 4). Dentre as consorciações com os cultivos a que mais favoreceu a produção de lenha foi o consórcio com palma, com valor médio de $14.880 \mathrm{~kg} \mathrm{ha}^{-1} \mathrm{MS}$, sendo $18 \mathrm{e} 78 \%$ mais lenha produzida que nos sistemas com milho+feijão e com buffel, respectivamente.

Quando comparadas as duas espécies arbóreas, agliricídia produziu mais lenha que a maniçoba. A média anual de produtividade de lenha da gliricídia foi de 10.829 , enquanto a da maniçoba foi de apenas $1.105 \mathrm{~kg} \mathrm{ha}^{-1} \mathrm{MS}$ (Tabela 4). De certa forma,este resultado poderia ser esperado pelo fato da gliricídia pertencer à família Fabaceae e ter potencial de fixar nitrogênio da atmosfera através de simbiose com bactérias diazotróficas. Resultados como este indicam que a gliricídias e adaptou muito bem às condições e da foclimáticas no semiárido, apesar de exótica. Por outro lado, a maniçoba, pertencente à família Euphorbiaceae, não fixadora, ainda é uma planta pouco trabalhada visto que só recentemente tem sido objeto de trabalhos de seleção e melhoramento feitos por instituições de pesquisas, como a Embrapa CPATSA (Embrapa Semiárido) e o INSA (Instituto Nacional do Semiárido). Em estudo anterior a gliricídia apresentou produção de lenha abaixo da verificada neste estudo (5.581 kg ha ${ }^{-1} \mathrm{MS}$ ) provavelmente em razão das condições edáficas desfavoráveis do Neossolo Regolítico em que foi cultivada (Pérez-Marin et al., 2007).

Somando as produtividades de biomassa das culturas e das arbóreas nos quatro anos de estudo, as do sistema CA foram 7, 16, 1,5 e 2 vezes maiores que as do sistema SA(Tabelas 2 e 4). Além da maior produtividade de biomassa total no sistema CA, nos quatro anos, o agricultor diversifica a oferta de produtos na propriedade.

Os coeficientes de variação $(\mathrm{CV})$ da produtividade de biomassa durante os quatro anos de experimento foram de 18,2 e $89,5 \%$, nos sistemas CA e SA, respectivamente. No sistema CA, para os três sistemas de cultivos, milho + feijão, buffel e palma ocorreu menor variação na produtividade total de biomassa, $16 ; 42$ e $12 \%$, respectivamente, que no sistema SA no qual os CV foram 91 e $70 \%$ para milho + feijão e buffel, respectivamente. Não foi possível calcular o CV da palma uma vez que sua biomassa acumulada foi quantificada apenas em 2008; a introdução das árvores nos sistemas de produção conferiu maior estabilidade à produção de biomassa.

No semiárido a variabilidade anual e os coeficientes de variação das chuvas podem ultrapassar $50 \%$. Coeficientes acima de 30\% indicam ambientes pouco estáveis, enquanto coeficientes em torno ou abaixo de $20 \%$ sugerem ambientes pouco influenciados pela variabilidade ambiental. Assim como a disponibilidade hídrica, a produção de biomassa é muito variável, uma característica indesejável para quem vive de atividades agrícolas. Com isto, o manejo dos agro ecossistemas deveria atenuar tais flutuações. As questões tradicionais e culturais ainda levam os agricultores da região no semiárido a insistir muito em cultivos solteiros com culturas anuais (milho, feijão, mandioca, etc.) que,na maioria das vezes, são insustentáveis (Sampaio et al., 2009).

Para Sampaio et al. (2009) em sistemas biológicos com alta variabilidade ambiental, a diversidade de atividades e fontes de renda tende a amenizar o efeito das flutuações; assim, a introdução de árvores no sistema confere maior resiliência aos cultivos associados, mitigando efeitos ambientais.

\section{Conclusões}

1. O sistema sem árvores produziu mais biomassa, em média $33 \%$, que o sistema com árvores.

2. No sistema com árvores o capim buffel foi a cultura com maior produtividade enquanto no sistema sem árvores os cultivos que mais produziram foram o buffel e o consórcio milho+feijão.

3. O sistema sem árvores produziu duas vezes mais massa seca de grãos e palhada que o sistema com árvores.

4. Dentre as espécies arbóreas utilizadas agliricídia produziu nove vezes mais biomassa de folhas, galhos finos e lenha, que a maniçoba.

5. Os coeficientes de variação da produtividade anual de biomassa foram menores nos sistemas com a presença de árvores.

\section{Agradecimentos}

Os autores deste trabalho agradecem à CAPES, o apoio financeiro concedido através da bolsa de mestrado; ao CNPq, pelo apoio financeiro,conforme os Editais MCT/CNPq 15/2007 (Processo 478138/2007-5), Edital MCT/CNPq 01/2005 (Projeto Imsear) e Edital MCT/CNPq/CT-Agro 43/2008 (Processo 574893/2008-3) e ao Inter American Institute for Global ChangeResearch (IAI) - Projeto Amfoods (CRN2-014). 


\section{Literatura Citada}

Barreto, A, C.; Fernandes, M. F. Cultivo de Gliricidia sepium e Leucaena leucocephala em alamedas visando a melhoria dos solos dos tabuleiros costeiros. Pesquisa Agropecuária Brasileira, v.36, p.1287-1293, 2001.

EMBRAPA - Empresa Brasileira de Pesquisa Agropecuária. Centro Nacional de Pesquisa de Solos. Manual de análise química dos solos, plantas e fertilizantes. 2.ed. Rio de Janeiro: Embrapa Solos, 1999. 370p.

Ferreira, A. L.; Silva, A. F.; Ferreira, L. G. R.; Braga, L. G. T.; Moraes, S. A.; Araújo, G. G. L. Produção e valor nutritivo da parte aérea da mandioca, maniçoba e pornunça. Revista Brasileira de Saúde e Produção Animal, v.10, p.129-136, 2009.

Ferreira, D. F. Sisvar - Programa estatístico. Versão 4.2 (Build 39). Lavras: Universidade Federal de Lavras, 2003.

Freitas, A. D. S.; Sampaio, E. V. S. B.; Santos, C. E. R. S.; Fernandes, A. R. Biological nitrogen fixation in tree legumes of the Brazilian semi-arid caatinga. Journal of Arid Environments, v.74, p.344-349, 2010.

Garrido, M. S. Adubação com gliricídia e esterco em culturas do semi-árido nordestino. Recife: UFPE, 2009. 80p. Tese Doutorado

Henriksen, I.; Michelsen, A.; Schlonvoig, T. Tree species selection and soil tillage in alley cropping systems with Phaseolus vulgaris L. In: Humid premontane climate: Biomass, production, nutrient cycling and crop responses. Plant and Soil, v.240, p.145-159, 2002.

Kasele, I. N.; Nyirenda, F.; Shanahan, F. J.; Nielsen D. C.; D'Andria, R. Ethephon alters corn growth, water use, and grain yield under drougth stress. Agronomy Journal, v.86, p.283-288, 1994.

Menezes, R. S. C.; Salcedo, I. H. Influence of tree species on the herbaceous understory and soil chemical characteristics in a silvo pastoral system in semi-arid Northeast ern Brazil. Revista Brasileira de Ciência do Solo, v.23, p.817-826, 1999.

Menezes, R. S. C.; Salcedo, I. H. Mineralização de N após incorporação de adubos orgânicos em um NeossoloRegolítico cultivado com milho. Revista Brasileira de Engenharia Agrícola e Ambiental, v.11, p.361-367, 2007.

Menezes, R. S. C.; Salcedo, I. H.; Elliott, E. T. Microclimate and nutrient dynamics in a silvo pastoral system of semiarid northeast ern Brazil. Agroforestry Systems, v.56, p.27-38, 2002.

Moreira, J. N.; Lira, M. A.; Santos, M. V. F.; Araújo, G. G. L.; Silva, G. C. Potencial de produção de capim buffel na época seca no semi-árido pernambucano. Revista Caatinga, v.20, p.22-29, 2007.

Mundus, S.; Menezes, R. S. C.; Neergaard, A.; Garrido, M. S. Maize growth and soil nitrogen availability after fertilization with cattle manure and/or gliricídia in semi-arid NE Brazil. Nutrient Cycling in Agroecossystems, v.82, p.61-73, 2008.

Muthuri, C. W.; Ong, C. K.; Black, C. R.;Ngumi, V. W.; Mati, B. M. Tree and crop productivity in Grevillea, Alnus and Paulownia-based agroforestry systems in semi-arid Kenya. Forest Ecology and Management, v.212, p.23-39, 2005.

Nair, P. K. R. Introduction to agroforestry. Dordrecht: Kluwer Academic Publishers, 1993. 499p.
Ngegba, M. S.; Mugasha, A. G.; Chamshama, S. A. O.; Kimaro, A. A. Tephrosia Biomass yield and soil fertility in one season relay intercropping with mayze in semiarid Gairo, Tanzania. Discovery and Innovation, v.19, p.25-35, 2007.

Oliveira, M. C. O capim buffel nas regiões secas do nordeste. Petrolina: Embrapa CPATSA, 1981. 19p. Circular Técnica, 5

Pérez-Marin, A. M. P.; Menezes, R. S. C., Salcedo, I. H. Produtividade de milho solteiro ou em aléias de gliricídia adubado com duas fontes orgânicas. Pesquisa Agropecuária Brasileira, v.42, p.669-677, 2007.

Prasad, J. V. N. S.; Korwar, G. R.; Rao, K. V.; Mandal, U. K.; Rao, C. A. R.; Rao, G. R.; Ramakrishna, Y. S.; Venkateswarlu, B.; Rao, S. N.; Kulkarni, H. D.; Rao, M. R. Tree row spacing affected agronomic and economic performance of Eucalyptus-based agroforestry in Andhra Pradesh, Southern India. Agroforestry Systems, v.68, p.253-267, 2010.

Reynolds, P. E.; Simpson, J. A.; Thevathasan, N. V.; Gordon, A. M. Effects of tree competition on corn and soybean photosynthesis, growth, and yield in a temperate tree-based agroforestry intercropping system in southern Ontario. Ecological Engineering, v.29, p.362 -371, 2007.

Sampaio, E. V. S. B.; Araújo, M. S. B.; Salcedo, I. H.; Menezes, R. S. C. Agricultura sustentável no semiárido Nordestino. 1.ed. Recife: UFPE, 2009. 152p.

Sampaio, E. V. S. B.; Menezes, R. S. C. Sustainable soil use in tropical south America - with Emphasis on Brazil. In: Tiessen, H. (org.). Capacity of Soils for Sustaing Production - A Global Overview, in Encyclopedia of Life Support Systems. Oxford: UNESCO-EOLSS, 2003. Cap.1, p.1-11.

Sanchez, P. A. Science in agroforestry. Agroforestry Systems, v.30, p.5-55, 1995.

Santos, A. F.; Menezes, R. S. C.; Fraga, V. S.; Pérez-Marin, A. M. Efeito residual da adubação orgânica sobre a produtividade de milho em sistema agroflorestal. Revista Brasileira de Engenharia Agrícola e Ambiental, v.14, p.1267-1272, 2010.

Shirima, E. J. M.; Njau, F. B. C.; Buza, T. J.; Kyamanywa; R. S. Cassava-like tree (Manihot glaziovii) in combating fodder, vegetable and fuel wood shortage in rural communities: It's potential uses and limitations in semi-arid areas of central Tanzania. Discovery and Innovation, p.90-97, 2002. Special edition.

Silva, T. O.; Menezes, R. S. C. Disponibilidade de micronutrientes catiônicos em solo arenoso após adubação orgânica. Revista Brasileira de Ciências Agrárias, v.5, p.328-335, 2010.

Silva, T. O.; Menezes, R. S. C.; Tiessen, H.; Sampaio, E. V. S. B.; Salcedo, I. H.; Silveira, L. M. Adubação orgânica da batata com esterco e, ou, Crotalaria juncea. I - Produtividade vegetal e estoque de nutrientes no solo em longo prazo. Revista Brasileira de Ciência do Solo, v.31, p.39-49, 2007.

Siriri, D.; Ong, C. K.; Wilson, J.; Boffa, J. M.; Black, C. R. Tree species and pruning regime affect crop yield on brench terraces in SW Uganda. Agroforestry System, v.78, p.65-77, 2010.

Sousa, C. S. Diversidade e atividade de fungos micorrízico sarbusculares em agrossistemas do semiárido paraibano. Recife: UFPE, 2009. 136p. Tese Doutorado

Wick, B.; Tiessen, H. Organic matter turnover in light fraction and whole soil under silvopastoral land use in semiarid Northeast Brazil. Rangeland Ecology and Management, v.61, p.275-283, 2008. 